Original article

\title{
Uptake of PPTCT services among HIV sero-positive pregnant women in Mumbai, India - A descriptive study
}

\author{
Shrikala Acharya ${ }^{a}$, Roshni Cynthia Miranda ${ }^{\text {b, *, Padmaja Keskar }}{ }^{\text {a,c }}$ \\ ${ }^{a}$ Mumbai Districts AIDS Control Society (MDACS), Acworth Complex, R.A. Kidwai Marg, Wadala West, Mumbai, 400031, India \\ ${ }^{\mathrm{b}}$ HBT Medical College and Dr. R. N. Cooper Hospital, Bhaktivedant Marg, Juhu, Vile Parle West, Mumbai, 400056, India \\ ${ }^{\mathrm{c}}$ Public Health Department, Municipal Corporation of Greater Mumbai, 3rd floor, F-South Ward Office Building, Dr Ambedkar Marg and Jagannath Bhatankar Marg \\ Junction, Parel, Mumbai, 400012 India
}

\section{A R T I C L E I N F O}

\section{Keywords:}

Antenatal care

ART linkage

Health services

\begin{abstract}
A B S T R A C T
Background: Prevention of parent to child transmission of HIV is a major programme to control the main cause of new HIV infections among children. The successful implementation of the programme requires timely linkages to testing, ART treatment, follow-up and care at various levels of the cascade. The study measures these key points in the Prevention of Parent to Child Transmission (PPTCT) programme which are crucial for achievement of elimination of neonatal HIV transmission.

Methods: The study is a retrospective observational cohort study based on records of services provided to HIV sero-positive pregnant women enrolled for antenatal care at the 36 PPTCT centres across Mumbai during the period April 2014 to March 2015 and their follow-up till pregnancy outcome till October 2015.

Results: In the Antenatal clinics, 1,20,892 pregnant women were tested for HIV during the study period, of which 520 (0.43\%; 95\% CI: $0.39-0.47)$ women tested positive. The median time of ANC registration is 22 weeks of gestation, median time to ART linkage following testing is 5 days and median duration of ART received by the ANC mother is 17.4 weeks. Of the total pregnancies (523), 85.1\% resulted in live births, $3.1 \%$ were induced abortions, $2.5 \%$ ended in spontaneous abortions and $2.7 \%$ in still births.

Conclusion: The successful implementation of the PPTCT programme is mainly dependent on the important linkages and follow-up for eliminating the transmission of HIV to newborns and for providing reproductive rights to HIV sero-positive parents without fear of transmitting the infection to the child.
\end{abstract}

\section{Introduction}

The National adult (15-49 years) HIV prevalence is estimated at $0.26 \%(0.22 \%-0.32 \%)$ for India in 2015 . The total number of people living with HIV (PLHIV) in India is estimated at 21.17 lakhs (17.11 lakhs-26.49 lakhs) in 2015 with children ( $<15$ years) accounting for $6.54 \% .{ }^{1}$ Mother to child transmission of HIV is the primary route of HIV transmission among children. The Prevention from Parent to Child Transmission of HIV (PPTCT) in India was launched in 2002 using a single dose Nevirapine; the triple drug prophylactic antiretroviral (ARV) regimen (Option B) was adopted in 2012. The lifelong multidrug ART for all pregnant and breastfeeding women (Option $\mathrm{B}+$ ) was implemented in January 2014. Antenatal care of HIV sero-positive pregnant women can contribute to the decrease in the transmission of HIV to the child and thus reduce the burden of HIV among children.
The primary objective of the study is to determine the antenatal care based on Option B + guidelines received by HIV sero-positive pregnant women throughout the Prevention of Parent to Child Transmission cascade of HIV in Mumbai. The secondary objective of the study is to understand the demographic and obstetric profile of pregnant women at first contact with the health services.

\section{Methods}

The study is a retrospective observational cohort study based on records of services provided to HIV sero-positive pregnant women enrolled for antenatal care at the 36 PPTCT centres across Mumbai during the period April 2014 to March 2015 and their follow-up till pregnancy outcome till October 2015. It includes all women who underwent counselling and testing for HIV by serological testing using

\footnotetext{
* Corresponding author.

E-mail address: drroshnicdsouza@gmail.com (R.C. Miranda).
} 
triple rapid antibody based HIV tests and were tested positive for antibodies to the HIV virus during their antenatal period at the centres. The study also includes women who were known to have sero-positivity to HIV who had newly conceived and registered at the antenatal clinics. It excludes pregnant women who availed PPTCT services at private centres not registered under the PPTCT programme in Mumbai.

At the PPTCT centres, the identification details and biological test results of the mother at the time of registration and important events throughout ANC period like ART linkage, delivery details, outcome of pregnancy are noted. The women are counselled to receive multidrug ART regimen throughout pregnancy, thereafter to be continued lifelong and provide exclusive breastfeeds to the child for 6 months.

The data collected was analysed using Microsoft Office Excel 2007 and IBM SPSS version 21.0. All the hypotheses were tested by two tailed test at 0.05 level of significance. Categorical data was summarised as frequency and percentages and analysed using Chi-square test. The confidence intervals for percentage are calculated using Wilson efficient-score method, ${ }^{2}$ corrected for continuity. Continuous variables were summarised as mean and standard deviation or as median and interquartile range and analysed by unpaired $t$-test, one-way ANOVA with post-hoc Bonferroni test and univariate ANOVA test.

\section{Results}

In the Antenatal clinics, 1,20,892 pregnant women were tested for HIV during the study period, of which 520 (0.43\%; 95\% CI: 0.39-0.47) women tested positive. The mean age of the participants was $26.5 \mathrm{yrs}$, with standard deviation of $4.8 \mathrm{yrs}$. The youngest participant was $16 \mathrm{yrs}$ old and the oldest one was 45 yrs. Among the study participants, 474 $(91.2 \%)$ were presently married, $2(0.4 \%)$ were separated, $13(2.5 \%)$ were divorced and remarried, $1(0.2 \%)$ was a widow, $11(2.1 \%)$ were widowed and remarried, 5 (1\%) were never married and $14(2.7 \%)$ were female sex workers who were never married. The order of the pregnancy ranged from 1st to 9th, with median (inter-quartile range) of 2 (2).

Table 1 shows the relation in time of events in the course of the antenatal period. The number of mother-child pairs who received atleast 24 weeks of ART in ANC period was 109 (21.0\%).

Out of the study participants, 233 (44.8\%) were newly diagnosed with HIV during this pregnancy, the remaining 287 (55.2\%) were known to be HIV positive previously. The known positives had a significantly higher mean age [27.2 (4.6)] as compared to newly detected women [25.8 (4.8)] $(\mathrm{p}=0.001)$.

As seen in Table 2, 71 (24.7\%) of known HIV sero-positive cases were having their first child and among the newly detected cases, 116 (49.8\%) were detected during the first pregnancy. The knowledge of HIV status did not affect the trimester at which the woman registered in the antenatal period ( $\mathrm{p}=0.051$, Table 3 ). However, the mean week of gestation at which the woman was registered was found to be significantly earlier among newly detected cases [mean - 21.2 (SD - 8.5)] as compared to the known positive ones [mean - 23.4 (SD - 10.6)] ( $\mathrm{p}=$ 0.012). Sixty-six (12.7\%) women reported directly in labour of which 44 were known to have HIV infection previously and 12 were newly

Table 1

Time of events in the course of pregnancy.

\begin{tabular}{llll}
\hline Measures & $\begin{array}{l}\text { Time of ANC } \\
\text { registration }^{\text {a }} \text { (In } \\
\text { Weeks) }\end{array}$ & $\begin{array}{l}\text { Time from Post-test to } \\
\text { ART initiation** (In } \\
\text { Days) }\end{array}$ & $\begin{array}{l}\text { Duration of ART } \\
\text { taken during ANC } \\
\text { period }^{\#} \text { (In Weeks) }\end{array}$ \\
\hline $\begin{array}{l}\text { Mean (SD) } \\
\text { Median } \\
\text { (IQR) }\end{array}$ & $22.4(9.8)$ & $17.2(30.1)$ & $19.3(12.1)$ \\
$\begin{array}{c}\text { Min.- } \\
\text { Max. }\end{array}$ & $1-40$ & $5(18)$ & $17.4(17.9)$ \\
\end{tabular}

${ }^{\text {a }} \mathrm{N}=520 * * \mathrm{~N}=322$ (Of the rest of the participants, 79 ANC women were on ART before the start of the present pregnancy, 42 were started on ART after delivery and 77 were not started on ART) $\# \mathrm{n}=401$. detected during labour. The duration in weeks of ANC period during which ART was given to mother is seen in Table 4.

The baseline CD4 count was not significantly different ( $\mathrm{p}=0.112$, Fig. 1) between known and newly detected HIV seropositive women. The outcome of the pregnancy also did not significantly vary based on baseline CD4 count. A univariate ANOVA was conducted to examine the effect of age groups, order of pregnancy, trimester of pregnancy when registered and previous knowledge of status of HIV on the baseline CD4 count. As seen in Table 5, there was no statistically significant effect of any of these variables on the baseline CD4 count, no significant differences were also observed due to interactions between these groups on the baseline CD4 count.

Of the total deliveries conducted, 89 (19.5\%) were by C-section and 367 (80.5\%) were vaginal deliveries. There were three twin deliveries. The outcome of the pregnancies was live-birth in 445 (85.1\%), Medical Termination of Pregnancy (MTP) in $16(3.1 \%)$, spontaneous abortion in $13(2.5 \%)$ and stillbirth in $14(2.7 \%) ; 5(1 \%)$ were transferred out and 30 (5.8\%) were lost to follow up before delivery. The mean gestational week at which the study participants who had spontaneous abortions were registered was 14.1 week (SD - 5.1). There was no significant difference between the gestational week at which the study participants registered when the outcome was a live birth [Mean - 23.0 (SD - 9.7)] or still birth [mean - 27.9 (SD - 7.8)] ( $\mathrm{p}=0.069)$. Among the participants who were aware of the HIV status prior to this pregnancy, 7 (2.4\%) medically terminated their pregnancy, while $9(3.9 \%)$ of newly diagnosed women underwent medical termination of the pregnancy. Of the former, one was first order pregnancy and among the latter, five were first order pregnancies.

\section{Discussion}

The study showed that pregnant women with HIV sero-positivity are availing antenatal services at a mean gestational age of 22.4 weeks ( \pm 9.8 weeks) with all being linked to receive ART services within a week (median 5 days) so that the mean ART coverage of the mother during antenatal period is 119.4 days ( \pm 93.9 days) with $15.2 \%$ receiving ART throughout the antenatal period.

The success of PPTCT programmes depends on the cumulative impact of attrition of mother-infant pairs at each step of the PPTCT cascade which includes a series of interventions, including attending antenatal care, HIV testing and accepting and adhering to antiretroviraldrug prophylaxis for themselves and their exposed infant. Only $15-30 \%$ of pairs in high-burden countries complete the cascade. ${ }^{3}$ In our study, the cascade until delivery, was completed by $21.0 \%$ pairs (ART in ANC for $\geq 24$ weeks) and $40.7 \%$ (ART in ANC for $\geq 12$ weeks). A higher coverage was reported in the study in Brazil where $52.7 \%{ }^{4}$ of newborns of the cohort benefited from the complete package of interventions under PMTCT.

The Mumbai PMTCT model is highly successful in terms of linking all HIV seropositive pregnant women to ART centres and thereby initiation of ART, however, as observed the time to linkage is about a week. A study in Kenya shows that this linkage time can be reduced to zero with integration of HIV treatment services with Antenatal care. ${ }^{5}$ A metaanalysis demonstrated that in three of the four studies included in the analysis, the proportion of eligible pregnant women receiving ART was higher in ANC clinics that had integrated ART (Mozambique, RR: 1.58; 95\% CI: 1.17-2.14; Jamaica, RR: 1.38; 95\% CI: 1.29-1.47; Zambia, OR: 2.01; 95\% CI: 1.37-2.95). However, in the fourth study done in Rwanda, ART coverage was not significantly higher in ANCs clinics that had integrated ART (RR: 0.90; 95\% CI: 0.70-1.10). ${ }^{6}$

The major barriers for PMTCT implementation were unfavourable attitude toward PMTCT, distance of health facilities, loss to follow up and non-adherence. ${ }^{7}$ Lost to follow up in our study was $5.8 \%$ as compared to other studies which reported percentages which ranged from $0.5 \%$ to $21 \%{ }^{4,8}$

The behavioural impact of HIV on fertility has been studied 
Table 2

Previous knowledge of HIV sero-positivity and order of the pregnancy based on age-group of the study participants [frequency (\%)].

\begin{tabular}{|c|c|c|c|c|c|c|c|}
\hline \multirow[t]{2}{*}{ Age group (In yrs) } & \multicolumn{3}{|c|}{ Known positives } & \multicolumn{3}{|c|}{ Newly detected } & \multirow[t]{2}{*}{ Total $(100 \%)$} \\
\hline & 1st Order & 2nd Order & 3rd or Higher Order & 1st Order & 2nd Order & 3rd or Higher Order & \\
\hline $16-19$ & $4(22.2)$ & $1(5.6)$ & $0(0)$ & $11(61.1)$ & $2(11.1)$ & $0(0)$ & 18 \\
\hline $20-24$ & $30(17.6)$ & $37(21.8)$ & $15(8.8)$ & $62(36.5)$ & $22(12.9)$ & $4(2.4)$ & 170 \\
\hline $25-34$ & $32(11)$ & $75(25.8)$ & $67(23)$ & $42(14.4)$ & $50(17.2)$ & $25(8.6)$ & 291 \\
\hline $35-45$ & $5(12.2)$ & $6(14.6)$ & $15(36.6)$ & $1(2.4)$ & $6(14.6)$ & $8(19.5)$ & 41 \\
\hline Total & 71 (13.7) & 119 (22.9) & $97(18.7)$ & $116(22.3)$ & $80(15.4)$ & $37(7.1)$ & 520 \\
\hline
\end{tabular}

Table 3

Previous knowledge of HIV sero-positivity and obstetric state of the study participants.

\begin{tabular}{lllll}
\hline & Known positives & Newly detected & Total & p value \\
\hline \multicolumn{2}{l}{ Order of Pregnancy } & & & \\
1 & $71(24.7)$ & $116(49.8)$ & $187(36)$ & $<\mathbf{0 . 0 0 0 5}^{\mathrm{a}}$ \\
2 & $119(41.5)$ & $80(34.3)$ & $199(38.3)$ & \\
3 & $62(21.6)$ & $24(10.3)$ & $86(16.5)$ & \\
4 & $24(8.4)$ & $7(3)$ & $31(6)$ & \\
5 or more & $11(3.8)$ & $6(2.6)$ & $17(3.3)$ & \\
\multicolumn{1}{l}{ Trimester when registered } & & & \\
I & $39(13.6)$ & $29(12.4)$ & $68(13.1)$ & 0.051 \\
II & $96(33.4)$ & $102(43.8)$ & $198(38.1)$ & \\
III & $152(53)$ & $102(43.8)$ & $254(48.8)$ & \\
\multicolumn{7}{l}{ Total } & $\mathbf{2 8 7 ( 1 0 0 )}$ & $\mathbf{2 3 3 ( 1 0 0 )}$ & $\mathbf{5 2 0 ( 1 0 0 )}$ & \\
\hline
\end{tabular}

a Significant at 0.05 level of significance. Chi-square test used.

Table 4

Duration of ART administered during ANC period to mother [frequency (\%)].

\begin{tabular}{lllll}
\hline Duration of ART & Known positives & Newly detected & Total & P value \\
\hline No ART in ANC & $59(20.6)$ & $60(25.8)$ & $119^{* *}(22.9)$ & $\mathbf{0 . 0 0 2}^{\mathrm{a}}$ \\
$\leq 8$ weeks & $42(14.6)$ & $39(16.7)$ & $81^{\mathrm{b}}(15.6)$ & \\
8-12 weeks & $26(9.1)$ & $28(12)$ & $54(10.4)$ & \\
12-20 weeks & $42(14.6)$ & $50(21.5)$ & $92(17.7)$ & \\
$>20$ weeks & $118(41.1)$ & $56(24)$ & $174(33.5)$ & \\
Total & $\mathbf{2 8 7 ( 1 0 0 )}$ & $\mathbf{2 3 3 ( 1 0 0 )}$ & $\mathbf{5 2 0 ( 1 0 0 )}$ & \\
\hline
\end{tabular}

a Significant at 0.05 level of significance. Chi-square test used. $* * 44$ ANC women were started on ART after delivery; 15 live births, 4 still births, 8 abortions, 14 MTPs and 34 Lost to Follow-up (LFU)/transfer outs were not started on ART.

b Includes 2 MTPs previously. ${ }^{9,10}$ The pregnancy rate after knowing about HIV status has been seen to decline by $48 \%$ from first to second parity after knowing HIV positive status as compared to $35 \%$ decline in those before knowing their status. ${ }^{9}$ This calls for better access to contraceptive methods for those who do not want a child. In our study, the induced abortions were $3.1 \%$ out of all the pregnancies and $2.4 \%$ among the known positives; in other studies, varied ranges were reported from a low of $0.8 \%$ in a study in Brazil $^{4}$ to as high as $50 \%$ among known HIV positive cases in Western Maharashtra. ${ }^{11}$ Among those who knew about their HIV status, seven underwent MTP. However, HIV status may not be the only reason for HIV-positive women to contemplate abortion as antiretroviral treatment (ART) is now increasingly available leading to longer and healthier lives for these women. A study in Brazil found out that the influential factors for those who considered Pregnancy Termination included fear of HIV transmission, fear of HIV-related stigma, family size, economic constraints, partner and provider influence. ${ }^{12}$

The C-Section rate in our study was $19.4 \%$ which is higher as compared to the rate for the general population in India according to NFHS 4 which was seen to be $17 \%$ for the year $2015-16$. The reason for the C-Sections, whether elective or emergency, was however not recorded in our study. A meta-analysis ${ }^{13}$ showed that Elective C-Section among HIV sero-positive women was associated with increased maternal morbidity compared with vaginal delivery and was associated with decreased infant HIV infection but not among women on combination ART or with higher $\mathrm{CD} 4^{+}$cell count.

The stillbirth rate in the present study was $2.7 \%$. A study in Cape Town reported stillbirth rate in the HIV-positive population as 17.1/ 1000 births which was higher than the general population with an odds ratio (OR) of 2.07 (1.5-2.8). ${ }^{14}$ The Every Newborn Action Plan (ENAP) targets national stillbirth rates (SBRs) of 12 or fewer stillbirths per 1000 births by 2030 . The estimated average global SBR in 2015 was 18.4 per 1000 births ${ }^{15}$ and for India it was 23 per 1000 live births in $2015,{ }^{16} 0.4 \%$

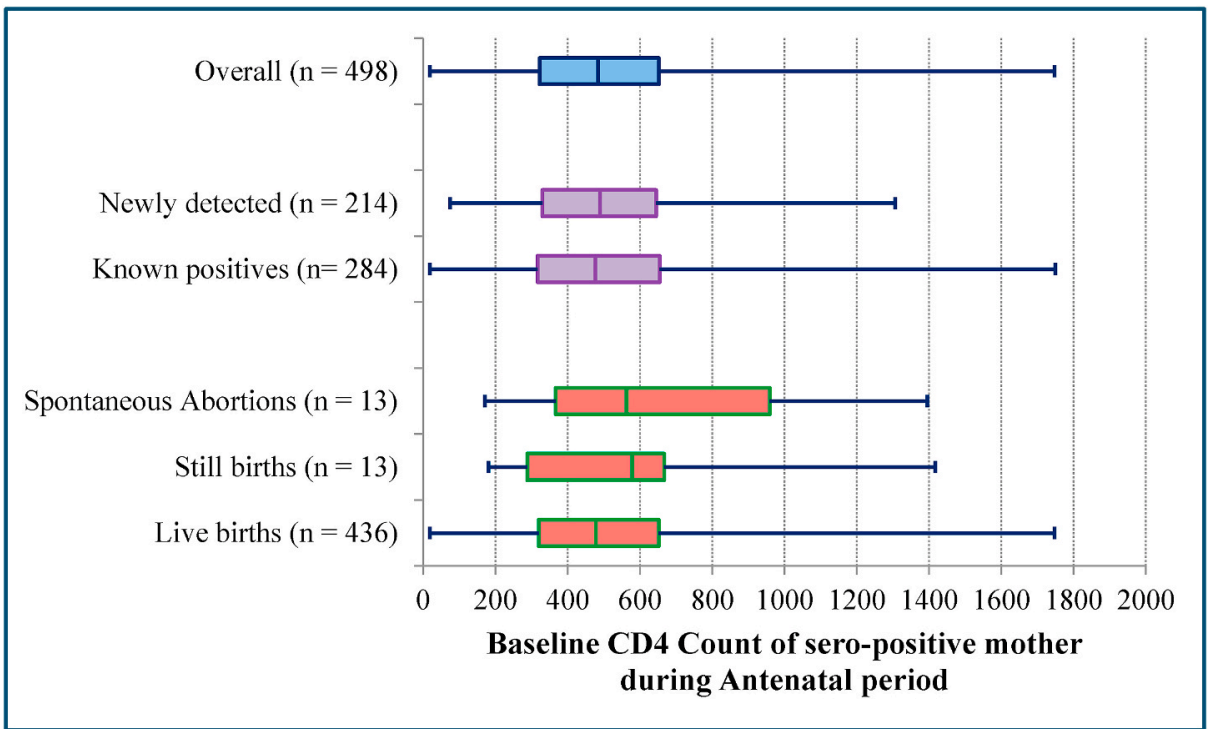

Fig. 1. Boxplot of the baseline CD4 count of the sero-positive pregnant women at the time of ANC registration.

The CD4 count was not significantly different in the above group of participants at 0.05 level of significance. For new and known cases, $\mathrm{t}=0.132, \mathrm{p}=$ 0.895 by independent sample $t$-test and for outcome of delivery, $\mathrm{F}(2,459)=3.081, \mathrm{p}=0.047$ by ANOVA test, however Bonferroni post-hoc test showed no significant difference between the groups. 
Table 5

Differences in Baseline CD4 count based on the age group, order of pregnancy, trimester when registered and previous knowledge of status of pregnancy.

\begin{tabular}{|c|c|c|c|c|c|}
\hline Variable & Category & $\begin{array}{l}\text { Mean (Std. } \\
\text { error) of } \\
\text { baseline } \\
\text { CD4 count }\end{array}$ & $95 \%$ CI & $\mathrm{F}$ & $\begin{array}{l}\mathrm{p} \\
\text { value }^{\#}\end{array}$ \\
\hline \multirow[t]{4}{*}{$\begin{array}{l}\text { Age group } \\
\text { (In yrs) }\end{array}$} & $16-19$ & $\begin{array}{l}643.1 \\
(80.3)\end{array}$ & $485.3-800.9$ & \multirow{4}{*}{$\begin{array}{l}F \\
(3,426) \\
=0.839\end{array}$} & \multirow[t]{4}{*}{0.473} \\
\hline & $20-24$ & $\begin{array}{l}581.1 \\
(34.7)\end{array}$ & $513-649.3$ & & \\
\hline & $25-34$ & $\begin{array}{l}494.4 \\
(26.4)\end{array}$ & $442.6-546.2$ & & \\
\hline & $35-45$ & $523(47.4)$ & $429.8-616.2$ & & \\
\hline \multirow[t]{5}{*}{$\begin{array}{l}\text { Order of } \\
\text { Pregnancy }\end{array}$} & 1 & $\begin{array}{l}577.7 \\
(30.9)\end{array}$ & $517-638.4$ & \multirow{5}{*}{$\begin{array}{l}F \\
(4,426) \\
=0.837\end{array}$} & \multirow[t]{5}{*}{0.502} \\
\hline & 2 & $\begin{array}{l}533.9 \\
(36.3)\end{array}$ & $462.5-605.4$ & & \\
\hline & 3 & $\begin{array}{l}600.6 \\
(43.3)\end{array}$ & $515.5-685.7$ & & \\
\hline & 4 & $\begin{array}{l}431.3 \\
(63.2)\end{array}$ & $307.2-555.5$ & & \\
\hline & 5 or more & $\begin{array}{l}452.6 \\
(78.5)\end{array}$ & 298.4-606.9 & & \\
\hline \multirow{3}{*}{$\begin{array}{l}\text { Trimester } \\
\text { when } \\
\text { registered }\end{array}$} & I & $\begin{array}{l}593.6 \\
(44.2)\end{array}$ & 506.9-680.4 & \multirow{3}{*}{$\begin{array}{l}\mathrm{F} \\
(2,426) \\
=2.412\end{array}$} & \multirow[t]{3}{*}{0.091} \\
\hline & II & $\begin{array}{l}526.3 \\
(33.3)\end{array}$ & $460.9-591.8$ & & \\
\hline & III & $\begin{array}{l}500.8 \\
(27.9)\end{array}$ & $446-555.6$ & & \\
\hline \multirow{2}{*}{$\begin{array}{l}\text { Knowledge } \\
\text { of status of } \\
\text { HIV }\end{array}$} & Known & $\begin{array}{l}525.3 \\
(25.6)\end{array}$ & $475-575.5$ & \multirow{2}{*}{$\begin{array}{l}F \\
(1,426) \\
=2.266\end{array}$} & \multirow[t]{2}{*}{0.133} \\
\hline & $\begin{array}{l}\text { Newly } \\
\text { diagnosed }\end{array}$ & $\begin{array}{l}548.9 \\
(31.2)\end{array}$ & $487.6-610.1$ & & \\
\hline
\end{tabular}

\#There is no significant difference of CD4 count based on Age groups, order or trimester of pregnancy and previous knowledge of status of HIV. Also, no significant interactions between these groups were seen. Univariate ANOVA test used.

of pregnancies for Maharashtra (2015-16). ${ }^{17}$ The still birth rate is influenced by maternal HIV status and also by use of triple drug ART regimen, with the SBR said to be higher in those on triple drug ART. ${ }^{18}$ This is an area which needs to be investigated further.

The study had a limitation as the HIV sero-positive women enrolled in private centres for ANC care could not be included in the study.

The Prevention of parent to child programme has been responsible for the lower rates of new infections among neonates. However, successful implementation of the programme has met with many barriers. Besides, the linkages need to be achieved in the least amount of time as would be possible. Further research is required to minimise these pathways. Our study brings forth need to investigate newer operational techniques to optimise the benefits from the programme.

\section{Source(s) of support/funding}

Nil.

\section{CRediT authorship contribution statement}

Shrikala Acharya: Conceptualization, Methodology, Investigation, Data curation, Writing - review \& editing, Visualization, Supervision, Project administration. Roshni Cynthia Miranda: Conceptualization,
Methodology, Software, Validation, Formal analysis, Investigation, Data curation, Writing - original draft, Writing - review \& editing, Visualization, Supervision, Project administration. Padmaja Keskar: Conceptualization, Investigation, Resources, Data curation, Writing - review \& editing, Supervision, Project administration.

\section{Declaration of competing Interest}

Nil.

\section{Acknowledgement}

Nil

\section{References}

1 National AIDS Control Organisation. Ministry of Health and Family Welfare, GoI. India HIV Estimations 2015 - Technical Report; 2015. http://naco.gov.in/sites/default/files/ India\%20HIV\%20Estimations\%202015.pdf. Accessed November 17, 2020.

2 Newcombe RG. Two-sided confidence intervals for the single proportion: comparison of seven methods. Stat Med. 1998;17:857-872.

3 Farrar J, et al. HIV/AIDS prevention. In: Reynolds SJ, Quinn TC, eds. Manson's Tropical Diseases. 23 ${ }^{\text {rd }}$ ed. vol. 12. 2014:100-111.e2. China.

4 Araujo ESP, Friedman RK, Camacho LAB, et al. Cascade of access to interventions to prevent HIV mother to child transmission in the metropolitan area of Rio de Janeiro, Brazil. Braz J Infect Dis. 2014;18(3):252-260.

5 Turan JM, Onono M, Steinfeld RL, et al. Effects of antenatal care and HIV treatment integration on elements of the PMTCT cascade: results from the SHAIP clusterrandomized controlled trial in Kenya. J Acquir Immune Defic Syndr. 2015;69(5): e172-e181.

6 Suthar AB, Hoos D, Beqiri A, Lorenz-Dehne K, McClure C, Duncombe C. Integrating antiretroviral therapy into antenatal care and maternal and child health settings: a systematic review and meta-analysis. Bull World Health Organ. 2013;91:46-56.

7 Legesse B. Quality and implementation barriers of prevention of mother to child transmission of HIV program in Ethiopia: a cross sectional study. Value Health. 2015 May 1;18(3):A275-A276.

8 Rawizza HE, Chang CA, Chaplin B, et al. Loss to follow-up within the prevention of mother-to-child transmission care cascade in a large ART program in Nigeria. Curr HIV Res. 2015;13(3):201-209.

9 Darak S, Hutter I, Kulkarni S, Kulkarni V, Janssen F. Occurrence of pregnancies among HIV infected Indian women: does knowledge about HIV status make a difference? Int J Popul Res. 2015. Article ID 578150, 7 pages.

10 Darak S, Janssen F, Hutter I. Fertility among HIV-infected Indian women: the biological effect and its implications. J Biosoc Sci. 2011;43(1):19-29.

11 Darak S, Hutter I, Kulkarni V, Kulkarni S, Janssen F. High prevalence of unwanted pregnancies and induced abortions among HIV-infected women from Western India: need to emphasize dual method use? AIDS Care. 2016;28(1):43-51.

12 MacCarthy S, Rasanathan JJK, Crawford-Roberts A, Dourado I, Gruskin S. Contemplating abortion: HIV-positive women's decision to terminate pregnancy. Cult Health Sex. 2014:16(2):190-201.

13 Kennedy CE, Yeh PT, Pandey S, Betran AP, Narasimhan M. Elective cesarean section for women living with HIV: a systematic review of risks and benefits. AIDS. 2017;31 (11):1579-1591.

14 Kennedy D, Fawcus S, Kroon M. The effect of maternal HIV status on perinatal outcome at Mowbray Maternity Hospital and referring midwife obstetric units, Cape Town. SAJOG. 2012 Jan;18(1).

15 Blencowe H, Cousens S, Jassir FB, et al. National, regional, and worldwide estimates of stillbirth rates in 2015, with trends from 2000: a systematic analysis. Lancet Glob Health. 2016;4:e98-108.

16 UNICEF. Maternal and Newborn Health Disparities India; 2015. https://data.unicef.or g/wp-content/uploads/country_profiles/India/country\%20profile_IND.pdf. Accessed November 27, 2019.

17 Ministry of Health and Family Welfare. GoI and the International Institute for Population Sciences. India: National Family Health Survey; 2018 (NFHS-4), 2015-16 http://rchiips.org/nfhs/NFHS-4Reports/Maharashtra.pdf. Accessed November 27, 2019.

18 Shapiro R, Dryden-Peterson S, Powis K, Zash R, Lockman S. Hidden in plain sight: HIV, antiretrovirals, and stillbirths. Lancet. 2016 May 14;387(10032):1994-1995. 